\title{
Ethical Reflections on Human Dignity in the Milieu of Public Health Care
}

\author{
Nishant A Irudayadason* \\ Professor of Philosophy and Ethics, Jnana-Deepa Vidyapeeth, Pontifical Institute of Philosophy and Religions, Ramwadi, \\ Nagar Road, Pune-411014, Maharashtra, India.
}

Received: 24 July, 2017; Accepted: 01 August, 2017; Published: 25 September, 2017

*Corresponding author: Prof. Dr. Nishant A Irudayadason, Professor of Philosophy and Ethics, Jnana-Deepa Vidyapeeth, Pontifical Institute of Philosophy and Religions, Ramwadi, Nagar Road, Pune - 411014, Maharashtra, India, Tel: 902876125; Email: nishant@jdv.edu.in

\begin{abstract}
We witness increase of ethical concerns in the domain of healthcare, thanks to the two great strides, the incredible development of science and technology, and the considerable improvement of human living standards. The researcher in this paper intend to limit the scope of his study to public healthcare, while excluding the genetic research, its clinical applications and the allied which belong to bioethics. The researcher, through this paper, makes a contribution to the debate between the protection of the community and respect for individual freedom in public healthcare. Four dimensions are discussed: ethical models that seek to impose themselves in public health, the principles of autonomy and the tensions they generate between the individual and the community, emerging challenges in the face of social inequality and the new currents of thought that aim to renew visions ethics of public health autonomy. These questions inevitably call for a relook on the concepts of human rights and dignity, and respect for life and autonomy, which ethical reflections may help us find answers to, undoubtedly touching upon several dimensions of health care and social life.
\end{abstract}

Keywords: Autonomy; bioethics; capability; rights; healthcare

\section{Introduction}

While considerable advances in biomedicine over the past half century have led to a remarkable development in bioethics, interest in public health ethics appears to be relatively recent. $[1,2]$ Many authors interested in ethics in public health adopt the ethical model favoured by bioethics, that is to say the principlism. [1] Thus, the ethical problem is expressed in the tension or the dilemma arising between the protection of the community and the respect of the freedom of the individual.

This ethical approach deserves closer examination to see if it fits well within the diversity of actions found in public health. How far do the values of some public health programs fit into the vision of autonomy in bioethics that has developed since the 1970s? Hence the question of whether this ethics responds to the character of public health. Therefore, a third question: is it necessary to develop an ethical approach specific to public health that differs from the ethical model followed in bioethics?
The article is divided into four parts. The first briefly discusses the recent evolution of the role of ethics in public health. The second part deals with autonomy from the way in which the tension between the individual and the community arises, both in terms of public health programs and that of bioethics. In the third part, we shall highlight the social inequality in accessing healthcare and the need to take this aspect into account while making ethical reflection. The critical analysis of this interpretation, in the final part, leads to deal with new currents of thought which aim to enrich the ethics of public health and to renew the ethical visions of autonomy.

\section{Ethics and Public Health}

Many authors who have recently written about ethics in public health have highlighted the novelty of this issue. [1-3] How can this delay be explained in comparison to the impressive renewal of ethics in the field of medicine?

Perhaps the first explanation lies in the belief that public health is seen as naturally ethical, since it is aimed at the good of the entire population. Here we can think of immunization programs for children or efforts to improve public hygiene. It is therefore a fundamentally ethical action; the relationship between ethics and public health is obvious. Secondly, there is no opposition between public health and the autonomy of the individual insofar as every individual has the responsibility to maintain his/her health. Thirdly, many health professionals are involved in setting up different types of clinics accessible to all. These three reasons show the favourable image of public health and help us to understand why bioethics did not immediately concern public health.

Ethics intervenes in public health on the basis of certain events that challenge the primacy of individual rights in the name of protecting the community. The spread of AIDS in the 1980s is the most significant event. It represents a sudden disruption in the implicit harmonious relationship between ethics and public health. At a time when it was believed that science had overcome 
the great epidemics that had been devastating humanity for centuries, the spread of aids perturbed the tranquillity of the general public. Thus, the AIDS pandemic required important ethical debates about the policies to be put in place and the decisions to be made. The classic problems such as quarantine, exclusion and surveillance encountered in cases of epidemics came to the fore, but in a completely new socio-cultural context. There were also new mechanisms such as drug testing, screening of people at risk and confidentiality of screening tests. The debates that took place were with regard to the respect for rights and freedom of the individuals. Gay rights advocates and other affected groups strongly criticize public authorities whose decisions, taken in the public interest, were likely to cause irreparable harm to people with HIV. Bioethics entered the field of public health based on concerns about respect for the rights of the individual in the context of the protection of society as a whole. [4]

The second ethical debate in public health emerged in the context of fight against smoking, particularly in North America. Given the large number of smokers in 1960s, the health of millions of citizens was considered at risk. This resulted in a long struggle between tobacco companies and citizen groups defending freedom of choice on one hand, and public health authorities and other groups of citizens supporting the need to impose limits on smokers to protect the health of the public on the other hand. Among other things, the argument for second-hand smoke was increasingly used: protecting the public is a priority that allows the freedom of others to be restricted. Although this struggle was clearly ethical and was carried out when bioethics developed, bioethics did not show any particular interest in the problem. Bioethics was mainly concerned with the question of the allocation of resources and the limitation of treatment that health authorities may have to decide. It thus brought ethical discussion back to its own preoccupations, whether to restrict or not the free choice of individuals.

These two debates bear witness to the growing presence of ethical concerns in the field of public health. Some, especially in European countries, even argue that the utopia of health at all costs and the ideology of "national health" that characterize contemporary public health and impose a new morality determining good and evil. [5,6] The decisions to be taken are "Biopolitical," to borrow the expression from Michel Foucault. The ethical structure that served as a reference to guide the debates was borrowed from the field of medical ethics. It was not until the late 1990s and early 2000s that research essays aimed at developing an ethical framework for public health appeared on a regular basis. Since the mid-1980s, however, some research works appeared sporadically, foreshadowing a reflection that would develop later. $[7,8,9]$ At the heart of all these reflections is the question of the tension between respect for the individual and the protection of the community.

\section{Public Health and Autonomy}

Historically, the great public health successes of the nineteenth century are not based on respect for the autonomy of individuals but on the change of environment in the large industrial cities, the best housing conditions, and better quality of water. Although microbial theory and vaccination promoted a more individualized preventive approach from the end of the nineteenth century onwards, the State's leadership in promoting the hygienic conditions necessary for better health for the entire population prevailed. [10] As a result of the debates over the well-known hypothesis of [11], it is not so much medical progress that has contributed to the improvement of population health in recent centuries, but changes in living conditions, whether these changes are the result of an invisible hand or of human action.

A heightened awareness of social inequalities in health and a renewed perception of the place of the citizen in social life have led to the recognition of a place to the citizen previously unknown to him/her. Public health authorities could not ignore the increasing emphasis on the rights of individuals in all spheres of society. They had to take this into account in their actions because they realized that good public health calls for the collaboration of citizens. Finally, the design of the "new public health," focusing on the determinants of health, required the expertise of the social sciences, who emphasized the relation between individuals and their environment. [12]

The various programs put in place by public health today bear witness to different forms of autonomy. At least four dimensions emerge clearly. Empowerment of the person constitutes the first dimension. The desire to respect the rights of the individual and to avoid the stigmatization of communities at risk of discrimination represents a second dimension of recognition of autonomy. Accountability of individuals to their own health refers to a third dimension. The invitation to the public to participate in the development of public health actions can be considered as the fourth dimension.

Many public health programs now aim to increase the ability of more fragile citizens to cope with the conditions of their daily lives in a constructive way: to increase their sense of competence. Empowerment is a process of taking charge of the individual by himself, whether at the family, professional, economic or social level. For empowerment refers to the way in which the individual increases his self-esteem, self-confidence, initiative and control skills. [13] Empowerment increases the person's ability to meet his/her needs, solve problems and mobilize resources to be in control of his/her own life.

The emergence of new infectious diseases makes public authorities increasingly aware of the risks of discrimination or stigmatization of some of their decisions. The codes of ethics, currently being developed for public health professionals, address this risk. While priority must be given to public health 
on some occasions, it is necessary to seek to do so in a way that respects human rights: "Public health should achieve community health in a way that respects the rights of individuals in the community" [14]. Respect for the autonomy of individuals is part of the concern of the health authorities who, in order to be effective, must also respect the values of the people.

The third form of autonomy concerns the responsibility of individuals for their health. The lifestyle of individuals has major consequences on their health, hence the obligation of responsibility. This view meets the position of a large section of public opinion which, believes that people can change their behaviour and thus contribute to improving their health. [15] This notion of responsibility corresponds to the classical conception, that is, the accountability of the actions of which the human subject is the author. Because individual behaviours play a major role in their health, health authorities will initiate programs that address their responsibility to improve their nutrition, reduce smoking, or promote physical activity. This vision of responsibility rests on the recognition of the autonomy of individuals. It is, however, a source of public health debates, with the risk that the burden of ill health rests on unhealthy lifestyles of the individual without taking into account that these individuals have no choice on the hazardous environment in which they live. This can lead to the danger of blaming the victim.

The fourth dimension involves citizen participation in public health policy-making. This dimension of autonomy is citizendriven. Public health can no longer be left to the authorities alone; it must become the responsibility of all social actors. This approach calls into question the classical paternalism of public health and favours interdependence and collaboration. This participation should even constitute a principle on the basis of an ethical practice in public health. [7]

How do these various forms of autonomy in public health relate to the vision of autonomy that has emerged in bioethics? The theme of autonomy is the heart of the American bioethics movement; it even gives it its meaning. It has now become indispensable in all western countries to the extent that a recent article in the French journal Éthique \& santé began as follows: "The principle of autonomy seems to have become today the alpha and omega of the Medical ethics". [16] The interpretation of the concept, however, will vary. Some insist on respect for the person. Kant's philosophy inspires this vision. Another interpretation is more "political", with autonomy defining itself as the right to be protected from decisions that an authority imposes on its own. [17] The opposition to medical paternalism explains the negative nature of this definition. The individual is sovereign.

In bioethics, although autonomy has primordial importance, it is not the only principle. It fits into principlism, a set of three other principles that are beneficence, non-maleficence and justice. From the point of view of principlism, bioethics is about solving the moral dilemmas posed by developments in biomedicine and the rights of patients. [19] Present biomedical ethics as a domain for resolving moral conflicts. From a certain point of view, principlism may appear to be entirely adapted to public health when its ethical concern is limited to the conflicts between respect for the rights of the individual and the requirements of protection of society as a whole. Bioethics and public health seem to face the same types of dilemmas. Indeed, ethicists adopt the principles of principlism as a framework for developing their vision of ethics in public health. [18] Some, while expressing dissatisfaction with the traditional principles of bioethics in dealing with ethical conflicts encountered in public health, nevertheless propose a similar approach, adding some principles to those already mentioned. [19] Others refuse this framework in the name of the specificity of public health in relation to bioethics. Bayer and Fairchild argue that "bioethics cannot serve as a basis for thinking about the balances required in the defence of public health". [4]Moreover, the principlism does not fit with the other three dimensions of autonomy: empowerment, individual responsibility for one's own health, and citizen participation in public health policy-making. These dimensions do not fit within the preoccupation of bioethics.

\section{Challenges Arising from Social Inequality}

The likely evolution of morbidity and technological innovation allows us to consider changing health needs and the health care delivery that will contribute both to accentuate the crisis of public healthcare system. In addition, the pathogenic characteristics of certain aspects of social change, the persistence of high unemployment, the effects of economic exclusion mechanisms, and the transformation of family structures will induce health needs that will be truly satisfied only by putting in place mechanisms to combat social exclusion.

The continuous technological innovation at work in the medical field is for its carrier of potential disruptions to the organization and practice of care to the extent that it will make a profound transformation of the health professions and foster the emergence of an expert medicine. Thus, medical imaging, new surgical techniques, the use of biotechnology, gene therapies, functional supportive techniques will only reinforce the dynamics of diffusion of technological innovations. New occupations will emerge at the interface between medicine and biology, or computer science, which will alter the traditional conception of the physician's role and the organization of the corresponding work.

Medical practice thus entering a period of doubt and questioning, is also illustrated by the growing difficulty of dialogue that should unite patients and doctors. This global crisis situation in the health care system is reinforced by the negative effects on the subjects undergoing it of a policy of economic constraint, the application of which does not alter the scope of the challenges to be faced and leads to a degradation of confidence in the relationship between physician and patient. This internal crisis in health care systems is reinforced by a growing vulnerability of individuals and social systems. It would be illusory to try to 
remedy the difficulties we have just encountered and hope to modify the present situation without taking into consideration the more global evolution of contemporary societies. Issues of access to care and social inequalities in health are paradigmatic in this regard.

Another issue is the cost of care and continuity of treatment. Even with access to care, more and more treatments are only partly reimbursed by insurance companies, as a result of the effects of economic constraints on health care systems: increase in user fees, payment of packages, cancellation or reduction of reimbursements for drugs. The problem is becoming more and more critical for chronic patients requiring many hospitalizations, long-term, ambulatory, and sometimes home-based treatment, which represent extremely high financial burdens for those concerned. Moreover, these health situations often have a negative influence on the living conditions of these people, who often have to stop working, change their social situation, become indebted and thus enter a process of impoverishment that Weakens and prevents them from accessing the system.

Indeed, the issue of access to care returns, beyond the single issue of the care system, to a global reflection on the precariousness and inequality. Precariousness means extremely heterogeneous situations, all of which reveal a triple rupture experienced by the person concerned: a break with the daily activity of participating in the functioning of a society, in particular through work; a relational breakdown that gradually leads to isolation; finally, a temporal rupture, in which a closed future gives less reason to fight. This triple rupture signals the dynamics of human situations that evolve towards social exclusion, situations that multiply. The existence of such a dynamic reflects a process of social vulnerability that few people can say with certainty that they will not suffer at some point. Social inequalities in morbidity and mortality, which are difficult to establish, are indisputable and tend to increase. Among the explanations of these inequalities, it is necessary to underline the importance of the social position. Social inequalities in health are not primarily the result of unequal use of the health care system, but rather a difference in exposure to risk factors and in the way they are translated into the lives of people.

From this perspective, ethics cannot be limited to the formulation of abstract criteria to clarify the practices or policies. We believe that it is anchored in the history of practices and collective projects. It is fundamentally linked to an individual and collective approach in which individuals try to bring together the stakes of a common human becoming and concrete places of responsibility in which ethical issues are experienced. So it is essential for us here to reflect on the conditions of an ethical approach to health systems that can communicate ethical vision as well as singular and collective experience from the perspective of practical transformation in order to uphold human dignity.

\section{New Ethical Approaches to Public Health}

This final part discusses some recent initiatives to develop an ethical framework that responds to the reality of public health. The model proposed by Daniel Callahan and Bruce Jennings will draw attention first followed by the model of Jonathan Mann and finally the approach of Amartya Sen. Our aim here is not to be exhaustive, but to show the diversity of approaches open for our reflection.

Focus on a values-based vision of ethics. From the outset, they recognize the poverty of the relationship between bioethics and public health. [2] The phenomenon, historically, is explained by the fact that bioethics is concerned with the good of the individual rather than with the health of the public and, until recently, the use of technologies and allocation of resources were more towards bioethics rather than collective health issues. In the past few years, public health has attracted much interest due to the increase in infectious diseases and the recognition of the determining influence of socio-economic conditions on the health of individuals and communities.

Callahan and Jennings believe that a dialogue between public health and bioethics should be privileged. This will allow for a deeper understanding of public health issues and broader concerns about bioethics. Dialogue will nevertheless remain difficult because of the profound difference between these two world-views: individualistic orientation of clinic-based bioethics and social concerns of public health.

To begin this dialogue, the first task is to characterize ethics: "If ethics is understood to be a search for those values, virtues, and principles necessary for people to live together in peace, mutual respect, and justice, then there are few issues in public health that do not admit of an ethical perspective. [2]

On the basis of this vision of ethics, which is not based on conflicts and dilemmas but on values, Callahan and Jennings structure their book. Their ethical perspective deserves our attention on two specific points. Throughout the text, the authors, faithful to their vision of ethics, refuse to restrict their discussion to the opposition between the protection of public health and the limitation of individual rights. Ethical issues vary according to the diversity of tasks of public health and the actors involved. They make it clear that the ethical approach depends on different factors. The variety of subjects, the context of the question under study and the plurality of perspectives impose a variety of modes of analysis. Circumstances may call for one or more approaches, such as professional ethics, applied ethics, and the ethics of advocacy or promotion of the rights of socially vulnerable persons. These different types of analysis enrich the field of public health and favour decisions that take into account the multiple dimensions of reality and go beyond the duality between the collective and the individual. 
The different dimensions of autonomy present in public health programs find their own space in this ethical approach. Capacity building, respect for individual freedoms, responsibility for one's own health and citizen participation, all have their place. They are not at first in opposition to one another, they are elements which can at times find themselves in tension but which also complement each other.

Mann's approach to public health and ethics is arguably one of the most innovative ones. By introducing human rights at the very heart of public health in his essay titled "Medicine and Public Health, Ethics and Human rights," Mann aims at transforming it and at the same time enriching bioethics itself. Mann states that "the relationships among medicine, public health, ethics, and human rights are now evolving rapidly, in response to a series of events, experiences, and struggles. These include the shock of the worldwide epidemic of human immunodeficiency virus and AIDS, continuing work on diverse aspects of women's health, and challenges exemplified by the complex humanitarian emergencies of Somalia, Iraq, Bosnia, Rwanda, and now, Zaire". [20]

Analysing further the relationship between public health and human rights, he examines three moments in this relationship. A first moment concerns "potential burden" of public health policies on human rights. This first relationship affects, among other things, the limitation of individual freedom and discrimination. "There is often an unspoken sense that public health and human rights concerns are inherently confrontational... Thus recent attention has been directed to a negotiation process for optimizing both the achievement of complementary public health goals and respect for human rights norms. [20]

The second relationship between public health and human rights concerns the health consequences of public health policies that violate human rights. These impacts have "adverse effects on physical, mental and social well-being". [20]If the violation of certain rights, such as the right not to be imprisoned under inhuman conditions or not to be tortured, has obvious effects on health, the same may apply to the limitation of other rights. The history of AIDS shows that respect for human rights can contribute to health promotion by fostering creativity. Among other things, "needle exchange was a classic example of an innovative, local response to a pressing local problem". [20]

Hence a third relationship: the promotion and protection of human rights cannot be separated from the promotion and protection of health. "Human rights offer a societal-level framework for identifying and responding to the underlyingsocietal-determinants of health". [20]This frame of reference opens up concrete avenues of action, as evidenced by the International Conference on Population and Development (ICPD) coordinated by United Nations and held in Cairo in 1994. Concerning reproductive health and population policies, the classic approach to public health would have emphasized the principle of individual choice by providing information and counselling. The Cairo conference has shifted the focus "to ensuring that women can make and effectuate real and informed choices about reproduction. And in turn, this is widely acknowledged to depend on realization of human rights. [20] Thus, by protecting and promoting health, public health policies contribute to the protection and promotion of human rights.

This triple relationship shows the relevance of human rights language to guide analysis and work at the societal level. It does not, however, exclude the role of ethics because of the various tasks that public health must undertake. In this respect, there is continuity and not an opposition between human rights and ethics. Unfortunately, public health does not yet have its declaration or its code of ethics setting out the principles that should guide the professionals in this field. This gap is explained by the fact that public health has not yet clarified its own identity by adopting a coherent framework for the analysis of the societal determinants of health. The human rights framework would make it possible to move from the various specific ethics to the various professions related to public health and to public health ethics.

Developing public health ethics calls innovative ways other than solving dilemmas in the same way as bioethics. To do this, we need a fresh look at public health and ethics, with the rights of the person acting as a link. This ethic agrees with the vision of Paul Ricœur that ethics must aim at "a good life lived with and for others in just institutions". [21] With respect to autonomy, Mann's proposal does not oppose respect for human rights with the requirements of protecting the health of the community. While there may be limits to the self-determination of individuals, the central thesis is to assert the adverse consequences of health resulting from human rights abuses. It implies that the promotion and protection of public health requires the promotion and protection of human rights. Mann thus reverses to some extent the classical vision of ethics in public health. Privileging the empowerment of individuals and groups, his approach promotes the willingness of people to be responsible for their health and the participation of citizens.

While Mann emphasizes the promotion and protection of human rights to promote and protect human health, Amartya Sen, the 1998 Nobel Prize laureate in economics, goes even further by introducing the notion of capability which he defines as "the various combinations of functioning's (beings and doings) that the person can achieve. Capability is, thus, a set of vectors of functioning's reflecting the person's freedom to lead one type of life or another". [22]For Sen, health is one of the most important elements of human life and an element of human capabilities. Health is at the heart of a conception of social justice that recognizes the need for equitable distribution and just training of human capabilities. [23]

In his analysis, Sen distinguishes the existence of public health services from factors contributing to good health and disease, such as eating habits, income, lifestyle, working conditions and the epidemiological environment. [23]"Indeed, it can be argued that some of the most important policy issues in the promotion 
of health are the allocation of resources to health, rather than only on distributive arrangements within health care. (e.g. the 'rationing' of health care and other determinants of health), on which a good deal of the literature on health equity seems, at this time, to concentrate". [23]

This priority given to the overall allocation of resources to health is based on Sen's vision of rights to certain capabilities. This approach emphasizes the importance of freedom of choice, individual diversity and the multidimensional nature of wellbeing. Sen, with the help of a few colleagues, developed a Human Development Index (HDI) that was adopted in 1990 by the United Nations Development Program; This index evaluates not only the economic output of a country but the level of human development from three dimensions that can be summarized: healthy living, literacy and decent living conditions.

Sen did not attempt to develop an ethical model for public health. Although he is an economist, he has become increasingly interested in the philosophical and ethical issues of public health, focusing on justice and equity in health. By introducing the concept of capability into the economic domain, he promotes new interpretations of autonomy and calls for a review of the public health ethics vision.

These three approaches to the ethics of public health that we have discussed so far show a diversity of perspectives. Some integrate better than others the different dimensions of the problem of autonomy. The closer these approaches are to the contemporary bioethics model, the less they succeed in integrating the diversity of forms of autonomy in public health. The closer they become to a community and societal perspective, the more they integrate the value of human dignity.

\section{Conclusion}

It may have been believed for a long period of time that the application of the principle of bioethics could solve the ethical problems raised by the question of public health actions. But the emergence of new problems at the beginning of the 21stcentury such as the effects of second-hand smoke and transnational infectious diseases calls for deeper ethical reflections. These new challenges are particularly complex and require a critical analysis of the equitable redistribution of services and care to the most disadvantaged groups. Their complexity also questions the very foundation of rights and freedom as well as the creation of individual aspirations and capabilities. An amalgamation of the principles of law, equity and support for the realization of individual capabilities should be at the heart of the ethical values that guide the policies of public health that would promote human dignity.

\section{References}

1. Nancy E Kass. An Ethics Framework for Public Health. American Journal of Public Health.2001;91(11):1776-1782.

2. Callahan D, Jennings B. Ethics and Public Health: Forging a Strong Relationship. American Journal of Public Health. 2002;92(2):169-176.

3. Ronald B, Lawrence O Gostin, Jennings B, Steinbock B. Introduction: Ethical Theory and Public Health. In public Health Ethics Theory, Policy and Practice. UK; Oxford University Press: 2007.

4. Bayer R, Fairchild AL. The Genesis of Public Health Ethics. Bioethics. 2004;18(16):473-492.

5. Skrabanek P. The Death of Humane Medicine and the Rise of Coercive Healthism. Suffolk; Social Affairs Unit: 1994.

6. Sfez L. Perfect Health: Criticism of a New Utopia. Paris; Seuil:1995.

7. Doxiadis S. Ethical Issues in Preventive Medicine. Dordrecht; martinus nijhoff Publishers: 1985.

8. Lappe M. Ethics and public health. In public Health and Preventive Medicine, 12th edition, edited by Maxcy-Rosenau-Last. Norwalk; Appleton-Century-Crofty :1986.

9. Dan E Beauchamp. The Health of the Republic: Epidemics, Medicine, and Moralism as Challenges to Democracy. Philadelphia; Temple University Press:1988.

10.Ashton J, Seymour H. The New Public Health. Buckingham; Open University Press: 1988.

11. Thomas Mckeown. The Role of Medicine-Dream, Mirage or Nemesis. London; Nuffield Provincial Hospitals Trust: 1976

12. Peter F, Sudhir A, Amartya S. Health Equity and Social Justice. In public Health, Ethics, and Equity, edited by Sudhir Anand, Fabienne Peter and Amartya sen. UK; Oxford University Press : 2006

13.Eisen A. Survey of Neighbourhood-based, Comprehensive Community Empowerment Initiatives. Health Education Quarterly. 1994;21(2):235-252.

14. Thomas JC, Michael S, Jack D, James VG. A Code of Ethics for Public Health. American Journal of Public Health. 2002;92(7):1057-1059.

15. Solomon K. Secular Morality. In Morality and Health, edited by Allan M Brandt and paul Rozin. New York; Routledge:1997.

16. Svandra P. Autonomy as an expression of capabilities. Ethics and Health. 2007 ; (2):74-77.

17. McCullough LB, Wear S. Respect for autonomy and medical paternalism reconsidered. Theoretical Medicine. 1985;6(3):295-308.

18. Raymond M, Jocelyne SA. Ethics and Public Health. Issues, values and normativity. Australia ; Society, Cultures and Health :2003

19. Tom L Beauchamp, James F Childress. Principles of Biomedical Ethics Third Edition. New York; Oxford University Press: 1989.

20. Mann J. Medicine and Public Health, Ethics and Human Rights. In New Ethics for the Public's Health, edited by Dan E. Beauchamp and Bonnie Steinbock. UK; Oxford University Press:1999.

21. Ricoeur P. Oneself as Another. USA; The Chicago University Press:1992.

22. Amartya Sen. Inequality Reexamined. USA; Harvard University Press: 1992.

23. Amartya Sen. Why Health Equity? In public Health, Ethics, and Equity, edited by Sudhir Anand, Fabienne Peter and Amartya Sen. UK ;Oxford University Press :2006. 